\title{
COORDINACIÓN Y COMPLEMENTARIEDAD ENTRE INSTITUCIONES DEL ESTADO: UN DESAFÍO EN EL MARCO DE LOS NUEVOS ENTORNOS DE LA SEGURIDAD INTEGRAL
}

Grab. Ronier Ramírez Sandoya (+) ${ }^{1}$

\begin{abstract}
Resumen
El presente artículo analiza la relevancia en el empleo coordinado y complementario de las instituciones del Estado en respuesta a eventos que exigen un enfoque integral frente a contextos de elevada incertidumbre y factores no esperados. El objetivo es mostrar la importancia de la interagencialidad en el cumplimiento de las directrices correspondientes de las instituciones, enmarcadas en sus competencias, previniendo la agudización de factores de riesgo y amenaza, y trabajando preventivamente en la neutralización de potenciales efectos negativos para el país y sus ciudadanos. Este trabajo constituye un estudio de caso específico del empleo de las Fuerzas Armadas en el control de la pandemia de la COVID 19, bajo la modalidad de interagencialidad con otras instituciones del Estado mediante la consolidación de sus líneas de acción operativa y táctica, reduciendo la velocidad de la propagación de la enfermedad, en la jurisdicción del Comando Operacional 4 "CENTRAL". Las operaciones ejecutadas se derivaron del cabal cumplimiento de la estrategia desarrollada por el Comando Conjunto de las Fuerzas Armadas, alineada a varios principios de la conducción política de la defensa y materializadas en la ejecución de las Órdenes de Operaciones No. 1 y No. 2 del Plan de Contingencia elaborado para enfrentar la COVID 19. El hallazgo principal constituye el manejo profesional y la responsabilidad social de las Fuerzas Armadas, en cumplimiento de la Agenda Política de la Defensa de Ecuador, mediante la coordinación con los organismos de control de los diferentes cantones y provincias bajo esta jurisdicción. La reflexión teórica se basa en la acción integral - concepto central - y su empleo pragmático por parte del C.O 4 "CENTRAL". La conclusión preliminar alude a la necesidad de afianzar formas operativas militares, de manera continua y simultánea con guías específicas para la acción coordinada, complementaria y unificada y el logro de impactos positivos de las operaciones, como en el caso de los resultados alcanzados durante el período de pandemia COVID 19.
\end{abstract}

Palabras clave: Acción Integral, coordinación interinstitucional, innovación operacional de Fuerzas Armadas

\begin{abstract}
This article analyzes the relevance of the coordinated and complementary employment of State institutions in response to events that require a comprehensive approach in the face of contexts of high uncertainty and unexpected factors. The objective is to show the importance of interagency in complying with the corresponding guidelines of the institutions, framed in their competencies, preventing the exacerbation of risk and threat factors, and working in anticipation to neutralize potential negative effects for the country and its citizens. This work constitutes a specific case study of the use of the Armed Forces in the control of the COVID 19 pandemic, under the modality of interagency with other State institutions through the consolidation of their operational and tactical lines of action, reducing the speed of the spread of the disease, in the jurisdiction of Operational Command 4 "CENTRAL". The operations carried out were derived from full compliance with the strategy developed by the Joint Command of the Armed Forces, aligned with various principles of the political leadership of the defense and materialized in the execution of Operations Orders No. 1 and No. 2 of the Contingency Plan prepared to face COVID 19. The main finding constitutes the professional management and social responsibility of the Armed Forces, in compliance with the Political Agenda for the Defense of Ecuador, through coordination with the control bodies of the different cantons and provinces under this jurisdiction. Theoretical reflection is based on integral action - central concept - and its pragmatic use by the OC 4 "CENTRAL". The preliminary conclusion alludes to the need to strengthen military operational forms, continuously and simultaneously with specific guidelines for coordinated, complementary and unified action and the achievement of positive impacts from operations, as in the case of the results achieved during the period pandemic COVID 19.
\end{abstract}

Keywords: Integral Action, inter-institutional coordination, operational innovation of the Armed Forces

\footnotetext{
'General de Brigada. Comandante del Comando Operacional 4 "Central". Fuerzas Armadas de Ecuador (+). EJÉRCITO ECUATORIANO
} 


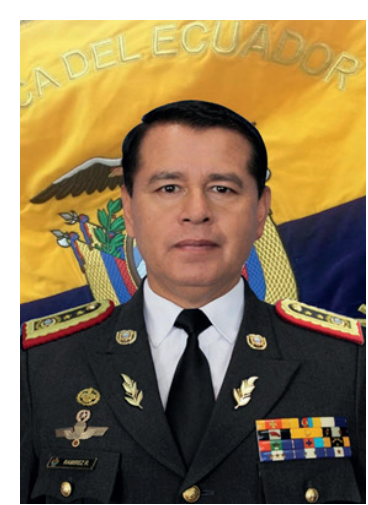

El General Ronier Bladimir Ramírez Sandoya nació el 14 de octubre de 1964, en el cantón Pindal, provincia de Loja, fue hijo del destacado padre de familia, político y emprendedor zapotillano Sr. Ángel Raúl Ramírez Correa y la matrona pindaleña Bertha Sandoya Espinoza. Su padre fue el primer jefe político del cantón Pindal, dedicado a la industria ganadera y su madre con su cariño y dedicación diaria logró formar en el general Ramírez un hombre lleno de valores éticos y morales. Posteriormente el general contrajo matrimonio con la Señora Ximena Albán y procrearon dos hijas: Estefanía y Ximena.

En el año de 1969 ingresó a la escuela Luis Urdaneta del cantón Pindal y en el año de 1976 estuvo en el Colegio Nacional "Pindal" hasta tercer curso, es así que en el año de 1979, da inicio a su destacada carrera militar al ingresar al colegio militar "Eloy Alfaro" de la ciudad de Quito, donde se destacó de manera muy exitosa, graduándose de bachiller con las mejores calificaciones. Ingresó a la Escuela Superior Militar "Eloy Alfaro" en el año 1982 donde se destacó por su gran liderazgo, inteligencia y fortaleza, y fue designado Brigadier, distinción que es otorgada a los cadetes más destacados en todos los ámbitos de la profesión militar. Se graduó de subteniente del Ejército el 9 de Agosto de 1985, su gran deseo de preparación para el servicio del país y convencido de que para liderar a sus soldados debe tener una preparación rígida, realizó el curso de comandos, donde obtuvo la primera antigüedad.

Realizó los cursos de paracaidismo, comando, jefe de salto, saltador libre, maestro de salto e instructor de Fuerzas Especiales. Se capacitó en Geografía Militar, Geopolítica y Derechos Humanos, Licenciado en Ciencias Militares, Diplomado en Economía de Defensa, Diplomado en Estudios Políticos y Estratégicos y Diplomado en Estudios Políticos Contemporáneos. Obtuvo el título de profesor de Geografía Militar y Geopolítica del Ejército de Chile.

En el año de 1995, en el grado de capitán, estuvo a cargo de la defensa de la soberanía nacional en Zapotillo, donde demostró las grandes dotes de un verdadero estratega militar y líder, manteniendo firme el sagrado territorio nacional en este sector del Ecuador.

Entre las principales funciones de comando y direccionamiento estratégico ejercidas se resalta: Comandante de la compañía de infantería N. 8 "ALAMOR", comandante del Batallón de Infantería Motorizado N. ${ }^{\circ} 19$ Carchi; jefe de instrucción de la Brigada de Selva N. 19 Napo; edecán del Ministro de Defensa Nacional; agregado de Defensa en la Embajada del Ecuador en los Estados Unidos; jefe del equipo asesor del Comandante General del Ejército; comandante de la Brigada de Fuerzas Especiales N. 9 Patria.

En el año 2019, por su gran trayectoria profesional, fue ascendido al grado de general de la república con la primera antigüedad. En el Grado de General fue designado Comandante de la Primera División del Ejército "SHIRYS”, donde estuvo liderando a sus soldados desde la primera línea en el control de las medidas para evitar la propagación del Covid 19 en toda la jurisdicción a su cargo; Pichincha, Cotopaxi, Tungurahua, Chimborazo, Bolívar, Santo Domingo y Los Ríos. Falleció el día viernes 19 de febrero del 2021, luego de afrontar una dura batalla ante el Covid-19. 


\section{Introducción}

$\mathrm{L}$ os seres humanos luchan permanentemente por satisfacer sus necesidades y por sobrevivir. Esta búsqueda por lograr sus objetivos es un generador de conflictos cuando se identifican aspiraciones comunes e intereses contrapuestos. Desde una perspectiva realista $^{1}$, quien tiene poder lo impone, afectando el relacionamiento entre las personas y grupos. Según Michel Foucault, una de sus primeras definiciones del poder $^{2}$ es que este es omnipresente, pues al ser asimétrico debe ser ejercido mediante alianzas o estrategias para garantizar la estabilidad en las interacciones entre actores (Foucault, 2015). Es más, la analítica del poder desarrollada por el autor (Durán, 2014) "está presente tangencial y centralmente en sus diferentes discusiones". En el mismo sentido, es vital considerar la condición ambivalente del poder porque permite tener una visión de la complejidad con la que el filósofo francés trató el tema en casi todos sus escritos. Foucault, de hecho, no consideró al poder como una cosa, sino como "el conjunto de estrategias y mecanismos que tienen como objetivo lograr victoria” (Durán Segura, 2014:61).

El anterior argumento debe ser complementado con una breve revisión de la literatura en Relaciones Internacionales y Teorías del Estado, en la medida en que ellas convergen en la relevancia del debate de lo internacional y del rol de los Estados en tal espectro, como contexto para la discusión de factores que aglutinan de igual modo a las reflexiones en torno a la seguridad. En este sentido, se evidencia un sinnúmero de posturas desde las más ortodoxas hasta las más críticas. Las principales corrientes teóricas son el realismo, el liberalismo y el constructivismo ${ }^{3}$, sin dejar de lado las posturas críticas consideradas heterodoxas. Todas ellas, de una u otra manera, han reflexionado en torno a la relación entre los Estados, al sistema internacional, a las dinámicas del poder, agendas e intereses en el campo de la seguridad.

Toda esta discusión se ha derivado en la construcción de explicaciones de la realidad internacional. De allí también se desprenden reflexiones en torno a los componentes domésticos en las diversas dimensiones (económica, política, seguridad, social, cultural, entre otras).

Las interpretaciones que subsisten hasta la actualidad son dos: la inspirada en la ciencia natural y económica, y una segunda que tiene relación con la explicación sociológica (Frasson-Quenoz, 2015). Estas teorías en su conjunto matizan la visión del Estado y las concepciones de la seguridad. Varios autores de las Relaciones Internacionales consideran que el campo

\footnotetext{
${ }^{1}$ Se entiende por realismo la corriente filosófica que defiende la objetividad, la existencia de los objetos en una realidad independiente de los sujetos, en la neutralidad valorativa de la investigación.

${ }^{2}$ En el desarrollo del pensamiento del filósofo hubo varias etapas y durante ellas el concepto de poder tuvo distintas acepciones difíciles de inventariar, catalogar y especificar por su variedad y constante autorrevisión (Durán 2014).

${ }^{3}$ En la actualidad los debates de las relaciones internacionales como disciplinas incluyen las reflexiones sobre la sociedad global.
}

de estudio de la seguridad es parte de la disciplina, mientras que otros, consideran a la seguridad dentro del ámbito de los Estudios Estratégicos (Booth, 2004). Este debate lleva a concebir el rol del Estado y la seguridad, y como en el caso del Estado ecuatoriano, se asume como concepción principal desde el año 2009 la seguridad integral y cooperación interinstitucional -que aparece formalizada desde el 2011- como base conceptual para el desarrollo de los documentos rectores del sector seguridad, defensa y de sus actores operadores.

La postura sostenida por Michel Foucault en torno a que la seguridad es el fin del Estado, y por ende la actuación del gobierno y del Estado deben estar relacionados entre todas las instituciones para garantizar controles intraorgánicos, neutralizando y evitando las diversas amenazas a la seguridad, es la que desarrolla este artículo y que se contempla en el Plan de Seguridad Integral 2019-2030.

\section{EI escenario global \\ I. Los escenarios global y local}

Las concepciones sobre el poder, la definición de las relaciones internacionales y las posturas sobre la seguridad permiten situar el problema materia de estudio de este trabajo, que es el estudio del caso ecuatoriano, sobre la seguridad. Para iniciar esta nvestigación es preciso determinar el escenario internacional donde prevalecen los intereses de los Estados. En un mundo globalizado el desarrollo de la tecnología incrementa la velocidad del cambio que exige que todas las instituciones evolucionen, que se adapten sistémicamente y atiendan las necesidades de la sociedad (Manucci, 2010). Alberth Einstein manifestó que, si se buscan resultados diferentes, se deben hacer cosas diferentes; por ello se requiere de flexibilidad por parte de sus actores con gran capacidad de adaptación, lo que es corroborado por la mirada del biólogo chileno Humberto Maturana en su concepción de la autopoiesis social (Maturana y Varela, 1980).

Estas consideraciones posibilitan comprender que el escenario VICA actual (volátil, incierto, cambiante y ambiguo) presenta amenazas asimétricas y multidimensionales que afectan a la seguridad, obligando a que los Estados enfrenten dichas contingencias con todas sus capacidades, por lo cual es vital asumir una conceptualización contemporánea de lo que constituyen "problemas complejos", categoría utilizada por el filósofo argentino Leonardo Rodríguez Zoya (2010). Consecuentemente, para enfrentar problemas multifactoriales se deben buscar respuestas multisectoriales, concurrentes y flexibles. En tal sentido, todos los elementos que pueda emplear el Estado para hacer frente a las amenazas deberán ser considerados de forma efectiva. Es más, es preciso disponer de un alineamiento interinstitucional adecuado mediante la construcción de voluntades políticas aunadas y compromiso con el bien común del Estado, sus ciudadanos y sus derechos para lograr, de manera 
eficiente y eficaz, el cumplimiento de los objetivos que se plantean en diversos campos, específicamente en el de seguridad. Por ello, el conjunto de los sistemas estatales debe adaptarse a esta nueva forma de respuesta frente a las amenazas emergentes y diversas necesidades imperantes. Ello implica un cambio de la mirada, un desafío de las maneras de concebir las nuevas realidades para la seguridad $y$, por ende, los nuevos ambientes operacionales para las Fuerzas Armadas y las distintas entidades e instituciones del Estado (Comando de Educación y Doctrina Militar Terrestre, 2020).

Vale recalcar que, al ser las amenazas volátiles, dinámicas, poco predecibles y amorfas, ellas demandan de grandes capacidades para enfrentarlas y el país tiene limitaciones.

El Estado, por ello, reduce sus posibilidades de intervención $\mathrm{y}$, por tal motivo, se va debilitando la institucionalidad y la gobernanza en seguridad. Dicho debilitamiento debe ser visto desde ya como una alerta temprana para el Estado y para el resto de los actores concurrentes, con el fin de propender el cambio de rutas de acción estratégica para enfrentar las hipercomplejas problemáticas de seguridad. Por ello, el involucramiento de Fuerzas Armadas exige nuevos procesos de planificación de operaciones en apoyo a las instituciones del Estado, mediante una adecuada y pertinente, planeación, preparación, ejecución y evaluación.

El liderazgo estratégico militar estudia y analiza de forma detallada los escenarios VICA ya mencionados. En dichos escenarios se han desplegado amenazas difusas e inciertas, detonantes de nuevas tipologías de conflicto impredecibles, lo cual implica en muchas ocasiones que la capacidad de defender y promover los intereses nacionales podrían ser restringidos justamente por limitaciones políticas, diplomáticas, comunicacionales y económicas (Shambach, 2004).

\section{El escenario local}

Este escenario constituye una adaptación de lo global enámbitos más específicos, con caracterizaciones propias y bajo comportamientos singulares y concurrentes de diversos actores. En otras palabras, exige ser mirado bajo una perspectiva multiescalar y multiactoral. En definitiva, la complejización de escenarios locales en respuesta a las problemáticas actuales de la seguridad ha sido considerada como elemento fundamental para la construcción de los documentos rectores, documentos normativos y legislación relacionada con estos nuevos ambientes que exigen una adaptación local.

Es así como el Art. 393 de la Constitución de la República del Ecuador indica que "el Estado garantizará la seguridad humana a través de políticas y acciones integradas, para asegurar la convivencia pacífica de las personas, promover una cultura de paz y prevenir las formas de violencia y discriminación, y la comisión de infracciones y delitos. La planificación y aplicación de estas políticas se encargará a órganos especializados en los diferentes niveles de gobierno" (Constitución de la República de Ecuador, 2008).

Asimismo, el Art. 3 de la Ley de Seguridad Pública y del Estado, establece que:

"La garantía de seguridad pública.- Es deber del Estado promovery garantizar la seguridad de todos los habitantes, comunidades, pueblos y nacionalidades y colectivos del Ecuador y de la estructura de Estado, a través del Sistema de Seguridad Pública y del Estado, responsable de la seguridad Pública y del Estado con el fin de coadyuvar al bienestar colectivo, al desarrollo integral, al ejercicio pleno de los derechos humanos y de los derechos y garantías constitucionales".

Este es el marco normativo que encuadra las acciones interagenciales las diferentes entidades estatales, pero específicamente entre el sector civil y el militar, defendiendo un principio de integralidad. Para complementar este argumento es pertinente mencionar al artículo agregado por la Ley publicada en Registro Oficial suplemento 63 del 9 de junio del 2014, en torno a la: Complementariedad de las acciones de Fuerzas Armadas a la Policía Nacional. - "con el fin de precautelar la protección interna, el mantenimiento y control del orden público y la seguridad ciudadana, las Fuerzas Armadas podrán apoyar de forma complementaria las operaciones que en esta materia competen a la Policía Nacional" (Ley de Seguridad Pública y del Estado, 2014: 4).

Matizando lo dicho, de igual modo la Ley Orgánica de Defensa Nacional estipula en las disposiciones generales: "Para el caso de desastres naturales y otras contingencias, las Fuerzas Armadas colaborarán con sus capacidades de prevención y respuesta inmediata, en apoyo a las autoridades e instituciones civiles responsables de atender dichas eventualidades" (Ley Orgánica de la Defensa Nacional, 2007 con modificación del año 2017, Disposición Sexta: 17).

En Ecuador, el "Libro Blanco" o Política de la Defensa Nacional fomenta la convivencia pacífica enmarcada en el respeto y aplicación de la legislación interna y el derecho internacional. Considera, de igual modo, el empleo del poder militar en la defensa de los intereses nacionales a través de una actitud defensiva y disuasiva, basado en la prevención y alerta temprana, empleando la fuerza militar para gestionar riesgos y contrarrestar amenazas estatales y no estatales, bajo el concepto de legítima defensa. Las prioridades estratégicas de la defensa consideran los intereses vitales relacionados con el ejercicio de los derechos fundamentales y los intereses estratégicos mediante la protección de los sectores y recursos estratégicos, enfrentando las amenazas y riesgos que afectan la seguridad del Estado (Ministerio de Defensa Nacional 2018b).

Es así como la emergencia sanitaria dio cuenta de la necesidad de contar con el contingente de las Fuerzas Armadas en primera línea. 
La política de la defensa nacional intenta fomentar la consolidación de la democracia y lo materializa mediante el fortalecimiento de las relaciones interinstitucionales creando condiciones seguras para su desarrollo, producción y bienestar, generando confianza en la población por el trabajo sinérgico entre las instituciones estatales y la sociedad civil. De este modo los niveles, dimensiones y resultados de la interagencialidad ${ }^{4}$ se sustentan en una necesidad de fortalecer la gobernabilidad, legitimidad y confianza del aparataje estatal en su conjunto.

El Ministerio de Defensa Nacional es el articulador del Consejo Sectorial de seguridad y coordina las acciones interinstitucionales, lo que facilita una interrelación entre los diferentes sectores que tienen la corresponsabilidad en el ámbito de la defensa y seguridad, articuladas a través de la Agenda de Coordinación Intersectorial (ACI), que orienta el cumplimiento de la planificación nacional y permite aterrizar en las operaciones a nivel táctico.

El espíritu de esta agenda impulsa el desarrollo de las operaciones interinstitucionales (Ministerio de Defensa Nacional, 2018). En otras palabras, para enfrentar la pandemia COVID 19 en el país, la participación de las Fuerzas Armadas fue vital -mediante el direccionamiento estratégico del Comando Conjunto y la delegación oportuna de operaciones a las diversas fuerzas de tarea-. Se considera que el apoyo a las instituciones del Estado como una operación militar especial permite cumplir la protección de derechos, libertades y garantías de los ciudadanos atendiendo a los marcos normativos amplios, decretos ejecutivos, acuerdos ministeriales, y normas referentes a los Derechos Humanos y Derecho Humanitario (Comando de Educación y Doctrina Militar Terrestre, Libro Fundamental, p.1).

Todo es posible mediante operaciones de apoyo, si se consideran que aquellas se estructuran con base en la operatividad, capacidad y división territorial que permita un control efectivo del territorio nacional, en el caso concreto para monitorear y neutralizar los efectos de la pandemia. Esto como una fase preliminar para que en lo posterior las autoridades civiles cuenten con las condiciones necesarias para continuar con la gestión de la emergencia sanitaria, sin el apoyo militar (Comando de Educación y Doctrina Militar Terrestre, AIE, Apoyo a las Instituciones del Estado, 2017: 27).

\footnotetext{
${ }^{4}$ Varias doctrinas para el empleo de las Fuerzas Armadas en apoyo de otras instituciones del Estado, como la colombiana, la estadounidense entre otras, hacen uso del término interagencialidad para hacer referencia a la estrategia de coordinación y complementación que exige el Estado entre sus diversas instituciones para garantizar su legitimidad en el control de riesgos y amenazas a la seguridad, mediante el uso de mecanismos específicos para la coordinación de acciones y el relacionamiento de esfuerzos individuales con objetivos comunes, en una verdadera convergencia entre lo militar y lo civil (Molano y Francoe, 2007).

${ }^{5}$ Esto implica una planificación clara y precisa para los diversos niveles de ejecución, cumplimiento y posterior evaluación sujetándose al marco legal pertinente direccionada a los escenarios y variables que se presenten (Comando de Educación y Doctrina Militar Terrestre, Manual Fundamental, 2020)
}

Dichos argumentos muestran la urgencia de conocer y considerar todas las herramientas y dispositivos con los que cuenta el país, para enfrentar profesionalmente y con oportunidad diversos tipos de contingencias amenazas emergentes y riesgos- que son susceptibles de presentarse.

\section{La planificación para las operaciones}

La Política de Defensa de Ecuador asigna al Comando Conjunto la misión institucional de planificar, preparar y conducir estratégicamente las operaciones militares y asesorar en torno a las políticas militares, de guerra y de defensa nacional. Vale señalar que, específicamente en este estudio de caso, las operaciones terrestres fueron planificadas de manera flexible y adaptada a los nuevos ambientes operacionales 5 .

De esta forma, se establecen líneas de acción de acuerdo con las misiones constitucionales que el Estado ecuatoriano entrega a las FF.AA., se citan a continuación las principales:

- Defender la soberanía e integridad territorial. Esta se materializa mediante el control de tierra, aire y mar, así como el ejercicio del control sobre las áreas reservadas y zonas de seguridad del Estado;

- Apoyar a otras instituciones del Estado, mediante la ejecución de operaciones de Contingencia Limitada y de Respuesta a las Crisis;

- Apoyar al desarrollo nacional en el ámbito de la defensa, a través de las instituciones respectivas;

- Contribuir a la paz regional y mundial (Ministerio de Defensa Nacional 2018b).

Ante la declaratoria de emergencia por la COVID 19 el Comando Conjunto de las Fuerzas Armadas inició su proceso de planificación atendiendo las directrices emitidas por parte del Ministerio de Defensa Nacional; para ello emitió sus planes y las órdenes de operaciones a partir de las cuales se diseñó y estructuró un modelo estratégico para conducir las operaciones militares de apoyo a las instituciones del Estado durante la pandemia de la COVID 19, alineado a la planificación nacional. Esta planificación debía ser flexible y adaptarse a la dinámica de los contagios y el avance de la enfermedad, así como a las múltiples afectaciones a la sociedad que generan nuevas demandas frente a la posibilidad de ocurrencia de eventos impredecibles que podrían afectar la seguridad de la población.

Las Fuerzas Armadas en este sentido, contribuyeron en acciones interagenciales de apoyo y complementariedad con las instituciones del Estado vinculadas directamente con el control de la pandemia, bajo un criterio de sostenibilidad en el tiempo (diversas fases de comportamiento de la pandemia) y con una clara concepción de sus propios procesos, actores y estructuras y sus capacidades de vinculación con las instituciones estatales.

Con ello logró zanjarse uno de los obstáculos para lograr resultados exitosos, cual es la coordinación efectiva entre dos tipos de organización institucional 
distintos: la cadena de mando militar y la burocracia civil $^{6}$.

Vale señalar que el Comité de Operaciones de Emergencia Nacional lideró las acciones mediante la toma de decisiones desde el inicio de la pandemia, posteriormente se activaron los COE provinciales y cantonales, que eran las autoridades que establecían las regulaciones que debían ser aplicadas en la medida en que se propagaban los contagios en el país. En consecuencia de las disposiciones del COE, el Comando Conjunto impartía las órdenes a los Comandos Operacionales para que sean ejecutados por las unidades militares, y en secuencia se emitían las Ordenes a los Grupos y Unidades Operacionales.

El modelo aplicado por las Fuerzas Armadas materializó el apoyo efectivo, dando cumplimiento a las medidas establecidas por el COE, de igual forma establecía la necesidad de la acción integrada, brindando el respaldo requerido a todas las instituciones en las actividades de control, a fin de disminuir la velocidad de avance de la pandemia, aludiendo a un sentido de "guiar y remar" simultáneamente hacia objetivos específicos claramente definidos y rutas de acción consistentes (Osborne y Gaebler, 1992).

Estas operaciones se basaron en los direccionamientos y propósitos principales del apoyo a las instituciones del Estado: salvar vidas; proteger las personas y colectividades; contribuir al mantenimiento o restauración de la ley y el orden; mitigar los riesgos; contribuir a la protección de la propiedad pública y privada, y contribuir a la protección del medio ambiente, sugeridos en el contexto del diseño del modelo. Este modelo consideró tres líneas operacionales que se derivan de la misión fundamental correlacionada con la misión complementaria de las Fuerzas Armadas, que permitió desde un enfoque integral, responder a las necesidades de la emergencia sanitaria, sin dejar de lado la defensa de la soberanía e integridad territorial (por ejemplo, patrullajes en fronteras, entre otros).

Dichas líneas se muestran en la Figura 1, a continuación:

\begin{tabular}{|c|c|c|}
\hline $\begin{array}{l}\text { Lineas } \\
\text { Operacionales }\end{array}$ & Fases & $\begin{array}{l}\text { Actividades desarrolladas por el personal del C.O } 4 \\
\text { "CENTRAL" }\end{array}$ \\
\hline Configuración & Prevención & $\begin{array}{l}\text { - Organizar, entrenar y actualizar los planes para un } \\
\text { posible empleo en apoyo al MSP. } \\
\text { Actualizar los estudios de área en cada jurisdicción, } \\
\text { orientados al contagio de coronavirus, coordinando } \\
\text { con instituciones competentes. } \\
\text { Capacitar al personal militar y sus familiares en } \\
\text { medidas de autoprotección, procedimientos a seguir } \\
\text { con contagiados en áreas de cuarentena y entrega de } \\
\text { equipo básico de protección contra el contagio de la } \\
\text { COVID 19. } \\
\text { - Proporcionar apoyo aéreo de mando y control y } \\
\text { transporte aéreo sanitario a otras instituciones. }\end{array}$ \\
\hline & $\begin{array}{l}\text { Contención } \\
\text { Inicial }\end{array}$ & $\begin{array}{l}\text { - Apoyar al MSP y a la P.N dentro del marco de las } \\
\text { limitaciones establecidas en el estado de excepción } \\
\text { (toque de queda). } \\
\text { Apoyar en el abastecimiento de artículos de primera } \\
\text { necesidad, transporte de insumos médicos, a } \\
\text { cualquier punto del territorio nacional a solicitud de } \\
\text { la institución pública que lo requiera. } \\
\text { Dotar de equipos de bioseguridad básico } \\
\text { (mascarillas, gafas, alcohol, guantes) al personal } \\
\text { militar con prioridad a los que se encuentran en } \\
\text { operaciones de apoyo. } \\
\text { Participar en los grupos de trabajo y mesas técnicas } \\
\text { de trabajo que integran el COE Nacional, provincial } \\
\text { y cantonal, mientras dure la emergencia. } \\
\text { Intensificar la difusión de campañas } \\
\text { comunicacionales de las medidas de restricción para } \\
\text { la prevención de contagio de la COVID-19. }\end{array}$ \\
\hline
\end{tabular}

\footnotetext{
${ }^{6}$ La toma de decisiones articuladas en un ambiente de cooperación y complementariedad se han aunado medios y esfuerzos para añadir valor y respuesta a la gestión pública en el objetivo clave del manejo de la pandemia.
} 


\begin{tabular}{|l|l|l|} 
& & $\begin{array}{l}\text { Proporcionar el tratamiento médico adecuado a } \\
\text { personal militar contagiado. }\end{array}$ \\
& Contención & $\begin{array}{l}\text { Intensificar el apoyo a la P.N en el control de la } \\
\text { población y los recursos, garantizando el flujo } \\
\text { logístico, en especial, de material e insumos } \\
\text { médicos, desinfección y limpieza. }\end{array}$ \\
& & $\begin{array}{l}\text { Establecer puntos de control interinstitucionales en } \\
\text { los límites provinciales para evitar el rompimiento } \\
\text { del cerco epidemiológico, control de actos violentos, } \\
\text { vandalismo y saqueos. }\end{array}$ \\
\hline Normalización & Estabilización & $\begin{array}{l}\text { Retorno del personal militar a sus unidades de origen } \\
\text { o jurisdicción. } \\
\text { Ejecutar operaciones de apoyo, mitigación, } \\
\text { restauración y recuperación de las actividades } \\
\text { públicas y privadas, de acuerdo con la situación y } \\
\text { jurisdicción }\end{array}$ \\
\hline
\end{tabular}

Figura 1. Lineas Operacionales del Comando Conjunto y fases del Plan de Contingencia para enfrentar a epidemia de coronavirus

Nota. Cuadro elaborado por el autor con base en información disponible en COVID-19 (Fuel, 2020).

La misión asignada a las Fuerzas Armadas consideraba el apoyo al Ministerio de Salud Pública, al Servicio de Gestión de Riesgos y Emergencias, a la Policía Nacional, a la Agencia Nacional de Tránsito, al Ministerio de Relaciones Exteriores y al Ministerio de Inclusión Económica y Social, en todo el territorio nacional.Elobjetivo central fue contribuira la contención, mitigación, restauración, recuperación y control de la epidemia, revirtiendo los tiempos y modalidades de riesgos de contagio y a la par, orientándose al mejoramiento de las condiciones de vida de la población desde un enfoque de acción unificada, que comprende los principios de sincronización, coordinación y/o integración con entidades gubernamentales (Comando de Educación y Doctrina Militar Terrestre, Apoyo a las Instituciones del Estado, 2020: 6).

Para ello se dispuso el cumplimiento de los protocolos, lineamientos y directrices, establecidos por el COE Nacional y el Ministerio de Salud Pública (MSP) y de las medidas de autoprotección del personal militar para estar en óptimas condiciones de empleo. Se dio preeminencia el apoyo de las Fuerzas Armadas con su capacidad logística en el transporte y entrega de medicinas, alimentos, evacuación médica requeridos por las instituciones con las que se estaba en proceso de coordinación y complementariedad.

De otro lado, se mantuvo como prioridad el apoyo a la Policía Nacional dentro del marco de sus competencias legales a los que fuere facultado legalmente a través de un decreto de estado de excepción, en el control de las restricciones y limitaciones de movilidad, control del orden público, actos violentos, control de centros de rehabilitación social, saqueos que puedan originarse a consecuencia de la crisis sanitaria, respetando en todo momento los derechos humanos y el uso necesario, proporcional y progresivo de la fuerza (Central, 2020).

\subsection{Organización y evolución de los eventos}

Para enfrentar la COVID19 en el Plan de Contingencia, el Comando Conjunto consideró emplear a la misma organización de las fuerzas militares de tiempo de paz, dividiendo el territorio nacional en cinco Zonas de Defensa con sus mandos y jurisdicción, empleando cinco Comandos Operacionales, más el Comando de Inteligencia Militar Conjunto, el Comando de Ciberdefensa y la Fuerza de Reacción.

El C.O 4 "CENTRAL" tiene su sede en Quito, y está formado por las unidades asignadas en la lista de tropas por el Comando Conjunto, las cuales se encuentran desplegadas en su jurisdicción que abarca siete provincias: Pichincha, Cotopaxi, Tungurahua, Bolívar, Chimborazo, Santo Domingo de los Tsáchilas y Los Ríos.

La fase de prevención se inició ante las primeras alertas en el mes de febrero sobre la progresión de contagios de la COVID 19 en el mundo, el Ministerio de Defensa a través del Comando Conjunto dispuso a todas las unidades que se preparen para el desarrollo de operaciones, y es así como las Unidades del Comando Operacional No. 4 iniciaron la preparación mediante la definición de los protocolos de atención y medidas de bioseguridad siguiendo las directrices de sanidad militar.

Las primeras acciones realizadas en el C.O 4 "CENTRAL", buscaron dotar de equipo de bioseguridad y capacitar al personal militar en el conocimiento de los diferentes protocolos, lineamientos, instructivos y regulaciones, poniendo especial énfasis en el apoyo a los organismos estatales, cantonales y parroquiales, y la observación y el respeto a los derechos humanos en la conducción de las operaciones.

Una vez que las autoridades sanitarias certificaron el primer caso de coronavirus (COVID19) en Quito el 
9 de marzo, ya para el 11 de del mismo mes se decretó Estado de Emergencia Sanitaria Nacional para controlar en el Ecuador la pandemia. Dos días después se informó de la primera persona fallecida en el país, la cual vino de visita al país y se encontraba en la provincia de Los Ríos. El 16 de marzo, mediante el Decreto Ejecutivo No. 101, se declaró el estado de excepción por calamidad pública en todo el territorio nacional, por la emergencia sanitaria.

Es así que en el país tan pronto como se identificaron las personas que se contagiaron en el extranjero y viajaron al país, se levantaron círculos epidemiológicos correspondientes para lograr una adecuada contención. Una vez que se conoció del primer caso importado, se aplicaron las medidas de aislamiento y control para que las personas enfermas no contagien a otros.

Las directrices sanitarias militares dispusieron que se preparen áreas de aislamiento preventivo obligatorio y áreas de aislamiento para el personal que tenía resultados positivos de COVID 19. Estas instalaciones contaban con los medios e infraestructura para la recuperación de las personas, examinadas de forma permanente por parte del personal médico de las unidades.

Además, entre las disposiciones emitidas para controlar el contagio del virus, se incluyó la aplicación de medidas estrictas de control en el aeropuerto de Tababela. Entre ellas, ingresos al país con exámenes negativos y/o cuarentenas controladas; estas medidas llegaron incluso a la prohibición del ingreso y el cierre de fronteras. Dichas medidas eran de obligatoria aplicación por parte de las autoridades y de riguroso cumplimiento por parte de los ciudadanos.

Al C.O 4 "CENTRAL" se le dispuso la planificación para recibir a los ecuatorianos que vivían en Wuhan y que retornaban al país luego de un proceso de cuarentena. La operación consideró la urgencia de aislamiento de dichas personas en las instalaciones de una unidad militar en esta jurisdicción. Es así como todas las personas y las familias debían aplicar medidas generadas para mejorar la seguridad y bioseguridad en sus domicilios y en las áreas comunes como espacios colectivos, en las que se debía aplicar medidas básicas de higiene evitando concentraciones, en cumplimiento de las regulaciones establecidas. El Estado dispuso la restricción de los ciudadanos a lugares públicos; a la par, se dispuso a las instituciones públicas aplicar la modalidad de teletrabajo para el desarrollo de sus actividades.

Ante las disposiciones del Comando Conjunto de las Fuerzas Armadas el 17 de marzo de 2020, se inició con el cumplimiento de las operaciones militares para enfrentar la epidemia del coronavirus en la jurisdicción de la Zona de Defensa No. 4, a fin de contribuir al mantenimiento del orden público, mediante la restricción de la movilidad, generación de responsabilidad y conciencia ciudadana en el cumplimiento de las medidas de salubridad establecidas por el COE Nacional. Con dichas medidas de aislamiento - establecidas en el estado de excepción- se dispuso la suspensión de las actividades productivas. Por lo cual, se cerraron los negocios que no ofrecían productos de primera necesidad, medicinas o insumos médicos; también las actividades académicas en escuelas, colegios y universidades fueron suspendidas.

Paralelamente, la movilidad fue restringida por la vigencia del toque de queda con lo cual se inició la cuarentena del país.

Todas estas actividades debían ser controladas para aplicar las regulaciones dispuestas. El C.O 4 "CENTRAL", ordenó a sus unidades que se realicen las coordinaciones con las entidades de control: Policía Nacional, Cuerpo de Bomberos, Agentes Metropolitanos de Control Metropolitano, Policía Metropolitana, Agentes de Control de Tránsito, Intendencias y Comisarías de las diferentes jurisdicciones, se conforme equipos interinstitucionales que permitían cubrir gran parte de las ciudades, en las actividades de control, enmarcados en las atribuciones y competencias que tiene cada institución. Esto dio como resultado una eficiente complementariedad y cooperación y se pudo alcanzar el objetivo previsto: reducir la velocidad de contagio en la jurisdicción. Así, se ejecutaron coordinaciones directas para la planificación de las operaciones, lo que facilitó la integración de esfuerzos, la optimización de recursos y la cobertura efectiva de las áreas que debían ser controladas.

En realidad, durante el desarrollo de las operaciones se constató que una buena parte de la ciudadanía acataba la restricción de movilidad, pero a la par también hubo quienes incumplían dichas disposiciones; este incumplimiento fue registrado en los denominados Reportes de Incivilidades del ECU 911 y medios de comunicación pública, por ello los funcionarios de las instituciones aplicaron los procedimientos legales establecidos.

En la medida en que se informaba al país en torno del incremento de los casos de contagiados individuales, se declaró el inicio del contagio comunitario. El virus se había propagado en la mayoría de las provincias del país. En los días 18, 19 y 20 de marzo se registraron los primeros casos de COVID 19 en las provincias del centro del país, Cotopaxi, Bolívar, Tungurahua y Chimborazo, lo que alarmó a la población. Entonces fue inminente desarrollar reuniones permanentes de los COE provinciales y cantonales, que mediante decisiones unánimes buscaron combatir la pandemia. Entre las principales acciones se activaron mesas técnicas de trabajo, de salud, alimentación y vivienda, abarcando diversos aspectos logísticos con la participación de todas las instituciones estatales.

De este modo, se implementaron medidas sanitarias restrictivas para evitar la expansión de la pandemia. Entre ellas se fijaron directrices sanitarias tales como el uso obligatorio de mascarilla y guantes, el mantenimiento de una distancia de mínimo de dos metros entre personas; la prohibición de aglomeraciones, desinfección de sitios de concentración masiva, entrega de kits alimenticios, y 
la búsqueda de lugares apropiados y estratégicos para la activación de centros de aislamiento temporal.

En las vías de acceso a las principales ciudades de toda la jurisdicción del C.O 4, se desplegaron controles interinstitucionales, para impedir el movimiento interprovincial y garantizar la movilidad de artículos de primera necesidad. Estos controles estuvieron a cargo de delegados de las Intendencias, Comisarías, Tenientes Políticos, Policía Nacional, Agentes Metropolitanos y Fuerzas Armadas.

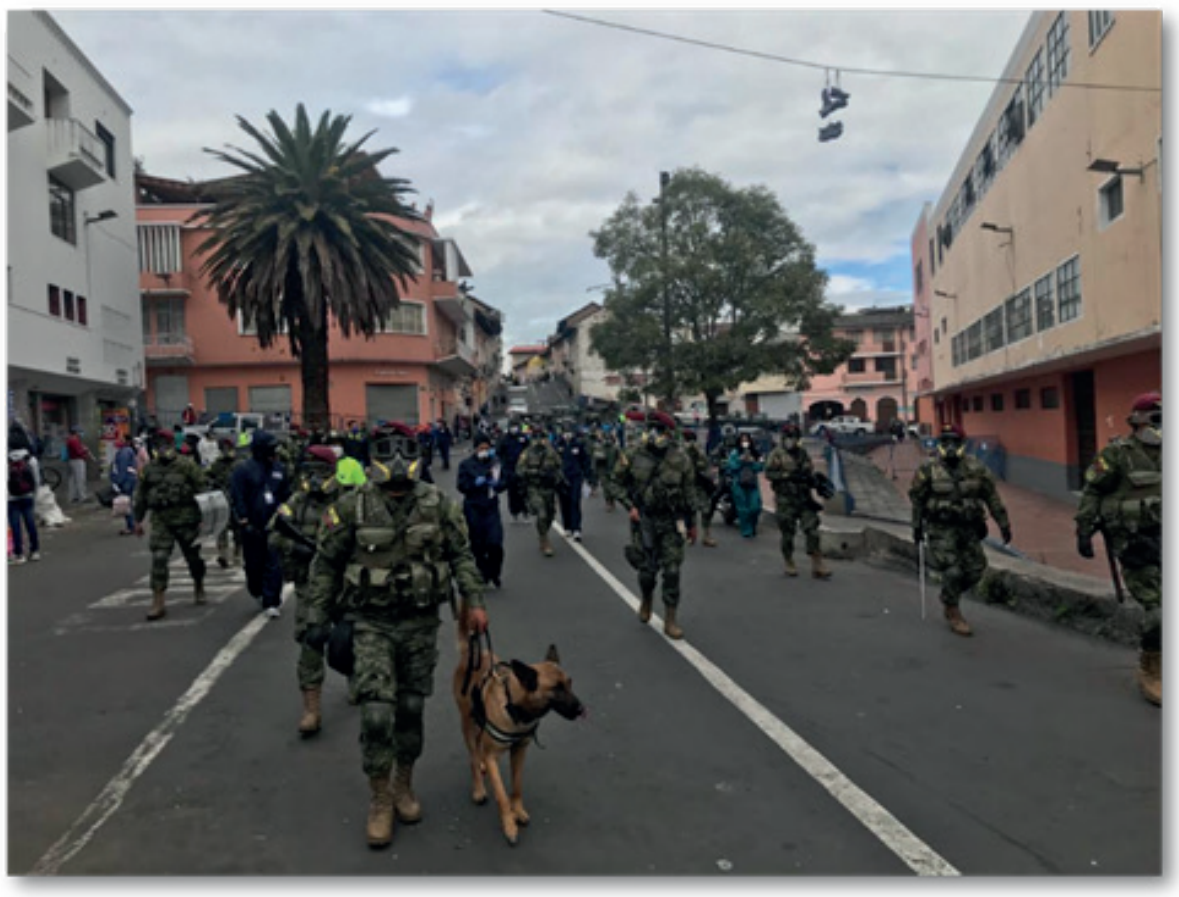

Figura 2. Personal de las unidades del C.O 4 "CENTRAL", se encuentran realizando patrullajes de control del toque de queda en apoyo a las instituciones del Estado.

Nota. Archivo fotográfico autorizado de OPSIC C.O 4 "CENTRAL"

El COE provincial de Los Ríos solicitó del COE Nacional, la búsqueda de lugares específicos que serían utilizados como fosas comunes debido a que por el incremento de contagios los índices de mortalidad se habían elevado. Esto a la par permitiría liberar la infraestructura que era requerida tanto para lugares de aislamiento temporal, como para lugares destinados a la atención médica de pacientes contagiados. Por este motivo, el Comando Operacional No. 4 "CENTRAL", el 20 de abril creo el Grupo de Tarea "Los Ríos", con un mando específico y los medios requeridos para el cumplimiento de la misión. De igual forma, se dispuso la coordinación con las autoridades locales de todas aquellas acciones para controlar de forma anticipada la propagación del virus. Dicha reorganización del dispositivo implicó mayor presencia militar en el área, a fin de garantizar una conducción de operaciones de manera coordinada. Estas acciones tranquilizaron a la población frente al control efectivo de la velocidad de los contagios.

Posteriormente, se implementó el toque de queda de 24 horas a nivel nacional y paralelamente se estableció el sistema de control de la población mediante la aplicación de la semaforización en el Ecuador. Todas las provincias fueron sometidas a las regulaciones establecidas para el color rojo. Ya para el 4 de mayo se particularizó la semaforización en cada provincia y cantón, delegando la responsabilidad de definición del color de semáforo a los COE respectivos con base en los indicadores de número de contagios, capacidad de reacción y ocupación de las instalaciones sanitarias.

Lo peor del caso fue que se incrementaron los contagios en Quito durante el mes de abril, ante lo cual, el COE Provincial de Pichincha y el Municipio del Distrito Metropolitano desarrollaron acciones interinstitucionales. Una de ellas fue la activación del punto de atención médica en el Centro de Convenciones Bicentenario, con una confiable capacidad de reacción ante el posible incremento del número de contagiados y de fallecidos por COVID 19; por ende, en este sitio se activó un Puesto de Mando Integrado. El personal militar del C.O 4 "CENTRAL" preparó y ejecutó la instalación con medios logísticos y apoyo al montaje de la infraestructura requerida para atender a la ciudadanía.

El 4 de mayo Ecuador pasó de la fase de aislamiento al distanciamiento social. Ante tal hecho, el Comando Operacional No. 4, acatando lo dispuesto por el Comando Conjunto emitió una nueva orden de 
operaciones. Esta incluyó disposiciones precisas y claras para los Grupos Operacionales hacia el cumplimiento de las nuevas regulaciones, la cuales exigían mayores coordinaciones con las autoridades e instituciones de control y el desarrollo de la planificación respectiva para la aplicación de las nuevas medidas de control.

Durante el mes de mayo se fueron adoptando acciones que permitieron el reinicio de las actividades productivas en varios campos. Mientras esto ocurría, se incrementaba el control de las aglomeraciones, para cuyo cumplimiento se establecieron horarios diferenciados en base al color de la semaforización del cantón.

Quito, al inicio del mes de junio pasó a semáforo amarillo, con modificaciones solicitadas por el COE Cantonal, para regular el transporte, el aforo de los locales y evitar aglomeraciones en lugares públicos. Dichas medidas permitieron la atención limitada de los negocios durante el estado de emergencia. Con todo, el retomar las actividades ocasionó problemas en el cumplimiento de las regulaciones sobre el uso de mascarilla, distancia segura y lavado de manos.

Posteriormente, mediante el Decreto Ejecutivo 1074, el 15 de junio de 2020 se estableció un nuevo estado de excepción en todo el país en el marco de la pandemia por COVID 19, argumentando la situación de "calamidad pública en todo el territorio nacional y por la emergencia económica que atraviesa el Estado ecuatoriano". Estas disposiciones buscaban mantener las medidas excepcionales como la restricción de la movilidad y de asociación que fueron la base del sistema de semáforo implementado para contener la propagación del virus.

Durante el mes de junio se exacerbó la crisis carcelaria en los Centros de Rehabilitación Social, por lo cual el personal militar C.O.4 "CENTRAL" diseñó operaciones de apoyo permanente a la Policía Nacional; dicha tarea demandó una planificación detallada del control en los Centros de Rehabilitación de la Jurisdicción. La planificación en mención diagnosticó la compleja realidad vivida por los CRS y las deficiencias en sus sistemas de seguridad.

Mientras tanto, aumentaba la preocupación por parte de la ciudadanía debido al incremento de casos positivos. No obstante, persistían los movimientos de algunas personas que salían a las calles de varias ciudades de la jurisdicción para comercializar frutas, legumbres y abastos de primera necesidad, con el fin de obtener ingresos económicos para su sustento diario y fortalecer la economía.

Para el 13 de agosto debido al incremento de casos de COVID 19 en el ámbito nacional, el COE estableció nuevos lineamientos para Quito y los cantones de 18 provincias de Ecuador como medida de contención del virus. Se prohibió la venta de bebidas alcohólicas de viernes a domingo y extendió el toque de queda para esos días desde las 19:00 hasta las 05:00. El 14 de agosto se anunció la ampliación del estado de excepción por calamidad pública en todo el territorio, esta medida entró en vigor con el Decreto 1126, que implicaba mantener la semaforización, el toque de queda y la restricción a las libertades de circulación y de reunión debido a la pandemia.

Debido al estado de excepción se determinó que el personal de Fuerzas Armadas debía apoyar el control de los Centros de Rehabilitación Social del país mediante la implementación del Primer Filtro de seguridad en los C.R.S medulares. Paralelamente, se controlaba a los existentes en la jurisdicción, coordinando operaciones de patrullaje en los exteriores de estas instalaciones.

A pesar de todas las medidas que se tomaron, se incrementaron de forma acelerada los casos de personas contagiadas en el Centro Histórico de Quito por el irrespeto a las disposiciones y las incivilidades en la ciudad. Se identificaron las parroquias de mayor incumplimiento de la normativa y se entregó la responsabilidad del control a las Fuerzas Armadas, Policía Nacional, Agentes del Municipio e Intendencia, quienes realizaron controles conjuntos en las parroquias de Guamaní, Belisario Quevedo, Chillogallo, La Magdalena, Centro Histórico, Cotocollao y Calderón. Las operaciones se planificaron con el objetivo de reducir la velocidad de contagio, impidiendo aglomeraciones y actividades clandestinas.

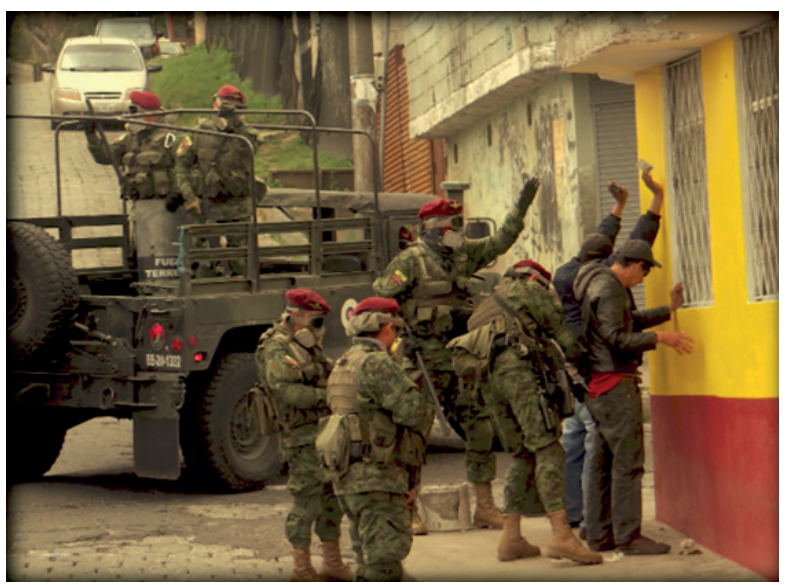

Figura 3. Personal militar realizando patrullajes de control en los barrios de Guamani y Cotocollao para controlar el crecimiento en el número de contagios de COVID 19.

Nota. Archivo fotográfico autorizado de OPSIC C.O 4 "CENTRAL"

Las medidas de bioseguridad fueron verificadas de modo permanente en la ciudadanía, tales como: el uso mascarilla, el respeto del distanciamiento, la verificación de los permisos de funcionamiento en los locales de negocios - cumplimiento de medidas de bioseguridad-, el control de porte de armas, el desarrollo de fiestas clandestinas, los libadores y el toque de queda. El 12 de septiembre el Servicio Nacional de Gestión de Riesgos informó la suspensión el estado de excepción decretado a partir del día 13 de septiembre. Durante este periodo de operaciones el personal militar desarrollo las siguientes tareas: 
- Operaciones CAMEX coordinadas con el personal de la Policía Nacional;

- Capacitación y control al personal militar de las unidades, a fin de precautelar la salud, estado físico y las condiciones empleo;

- Apoyo a la Policía Nacional en la corresponsabilidad para el control de restricción vehicular y peatonal materializando puntos fijos de control;

- Apoyo a las Instituciones del Estado, brindándoles seguridad a la Policía Nacional, Agencia Metropolitana de Tránsito (AMT), Ministerio de Salud Pública (MSP), Cuerpo de Bomberos, en el control del toque de queda, mediante patrullas móviles;

- Apoyo a la Policía Nacional y Centros de Rehabilitación Social, ejecutando operaciones de CAMEX y seguridad externa;

- Apoyo a los GAD y al MIES en la entrega de kits alimenticios en los sectores más vulnerables de nuestra jurisdicción;

- Patrullaje permanente en los sectores populares, mercados, lugares de concurrencia de la ciudadanía y del espacio público;

- Controles en los corredores logísticos para mantener la seguridad del transporte de alimentos en el sector de responsabilidad;

- Control permanente al ingreso y salida de las provincias;

- Participación activa en los COE Cantonales;

- Persuasión a la ciudadanía del inicio del toque de queda a fin de que se dé cumplimiento a lo dispuesto por el COE Nacional, apoyando el control de salvoconductos;

- Seguridad Hidrocarburífera, mediante el patrullaje permanente de la línea de oleoducto, estaciones y válvulas en la jurisdicción;

- $\quad$ Seguridad de las A.R.S de la jurisdicción mediante patrullaje permanente;

- Patrullaje antidelincuencial con la Policía Nacional en las áreas en las que podría suscitarse actos de vandalismo (saqueos).

En este sentido fue vital la conformación del Agrupamiento Táctico "PINDAL", para proporcionar apoyo a la Policía Nacional y a otras instituciones del Estado, en las operaciones de control, planificadas para mitigar la propagación del virus. Dicha unidad se formó con el contingente de personal militar integrado por unidades orgánicas del C.O 4 y unidades agregadas, al que se le asignó la misión de cumplir operaciones de control de armas, municiones y explosivos, apoyo al cumplimiento de las medidas impuestas por el C.O.E. Los equipos interinstitucionales estaban conformados por personal de las cinco entidades de seguridad del Distrito Metropolitano de Quito, quienes ejecutaban actividades de control, enmarcados en sus competencias específicas, con lo cual se daba paso al desarrollo de controles integrales.
Para el desarrollo de estas operaciones se impartió la instrucción de CAMEX, empleo del Pelotón Antidisturbios y motines, y el uso progresivo $\mathrm{y}$ diferenciado de la fuerza. Uno de los aspectos en los que se puso mayor énfasis fue el respeto a los Derechos Humanos, el conocimiento de las disposiciones del COE y la aplicación de la normativa de bioseguridad en vigencia. El personal militar en su totalidad estuvo equipado con material contra disturbios para su empleo. No se entregó armamento letal para esta operación.

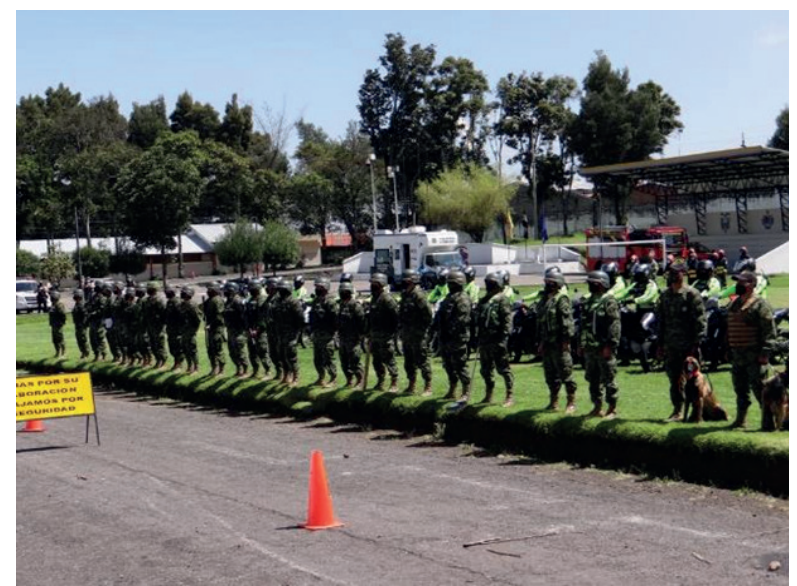

Figura 4. Los medios de comunicación pública reconocieron la presencia militar en las operaciones de control. Estos medios ayudaron a difundir las operaciones realizadas.

Nota. Archivo fotográfico autorizado de OPSIC C.O 4 "CENTRAL"

Las operaciones interinstitucionales son el hallazgo palpable de los resultados efectivos en la coordinación y la complementariedad entre los organismos de control en cumplimiento de sus competencias permitiendo el cumplimiento de la ley de las regulaciones establecidas. Durante la vigencia de los Estados de excepción para controlar la pandemia de la COVID 19 y para apoyar al control de los Centros de Rehabilitación Social el Comando Operacional No. 4 "CENTRAL" actuó de manera profesional teniendo claro el cumplimiento de la misión asignada: la efectiva coordinación con los organismos del Estado y con las instituciones de control en los cantones.

El numérico de las operaciones ejecutadas y los resultados obtenidos se presentan en la infografía de la página siguiente. 


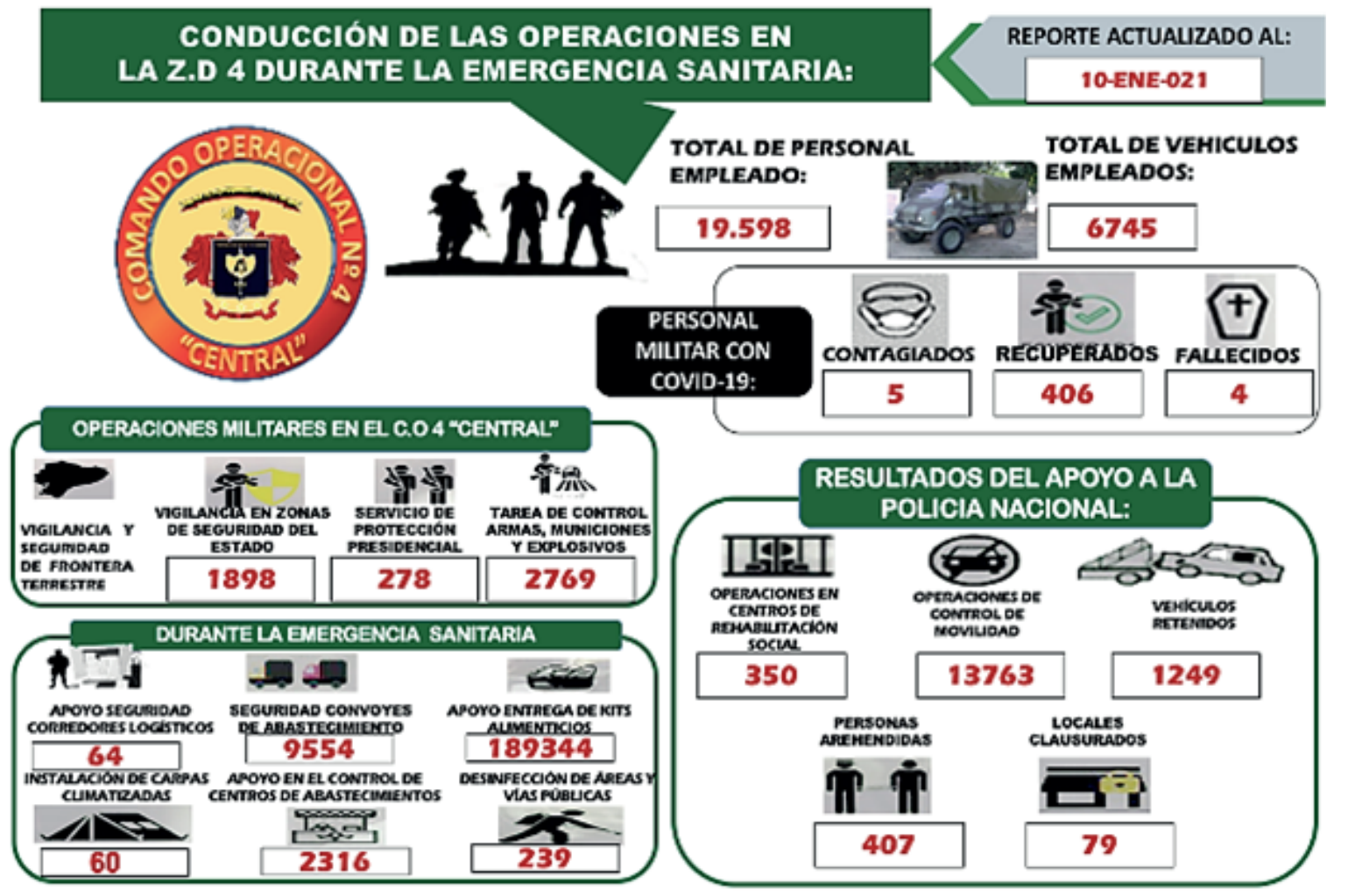

Figura 5. Infografía de las operaciones conducidas por el C.O 4 "CENTRAL", durante la emergencia sanitaria.

Nota. Elaboración basado en información del Departamento de Operaciones del C.O 4 "CENTRAL"

La infografía devela la integración y complementariedad de las instituciones del Estado. Se hace especial referencia a las carpas climatizadas, instaladas en diferentes hospitales, para el tratamiento de los pacientes contagiados de COVID19, es decir, conocer las capacidades que tiene cada institución, para coordinar, complementar o unificarse entre ellas, conociendo de antemano sus fortalezas y debilidades.

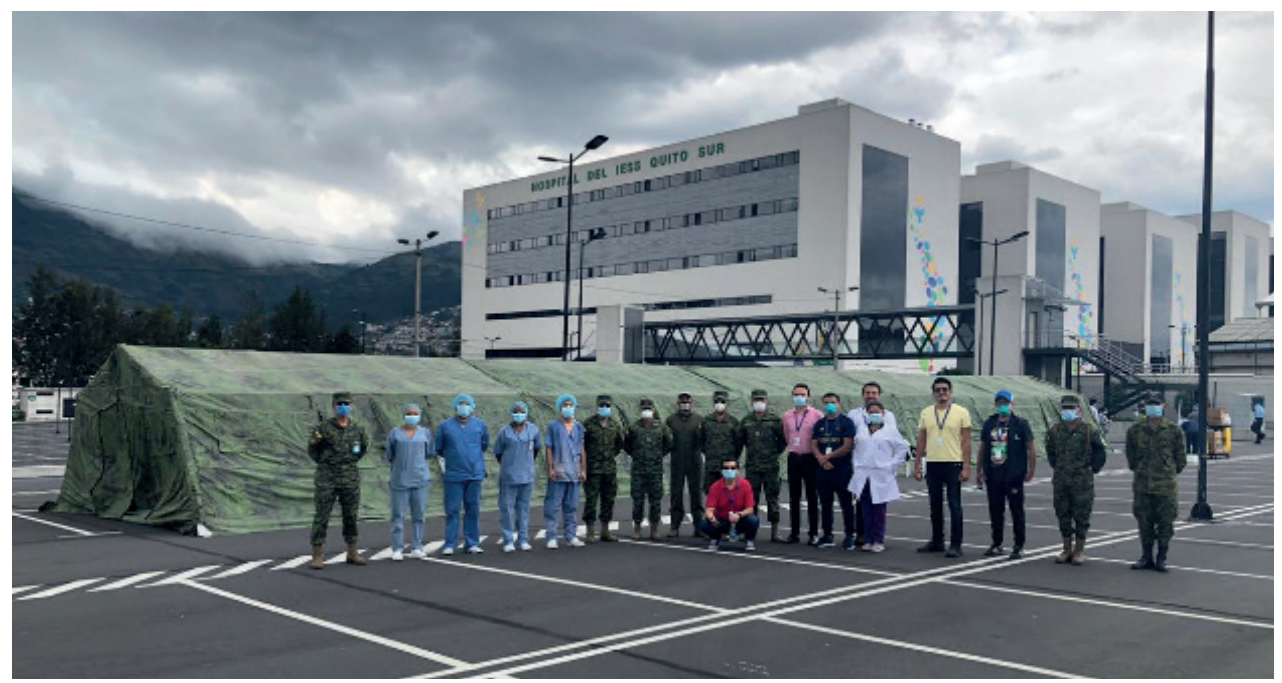

Figura 6. Instalación de carpas climatizadas en el hospital del IESS del Sur, para atención de pacientes COVID-19 Nota. Archivo fotográfico autorizado de OPSIC C.O 4 "CENTRAL"

Los medios de comunicación pública y las redes sociales informaron a toda la población sobre el desarrollo de las operaciones coordinadas con todos los organismos del Estado y agencias cantonales. Dicha información amplió el espectro del conocimiento de los ciudadanos respecto de las operaciones interagenciales militares como medidas de apoyo a la ciudadanía frente al COVID 19. Esto permitió legitimar el posicionamiento de las acciones militares en apoyo a la bioseguridad y las políticas públicas del Estado. 


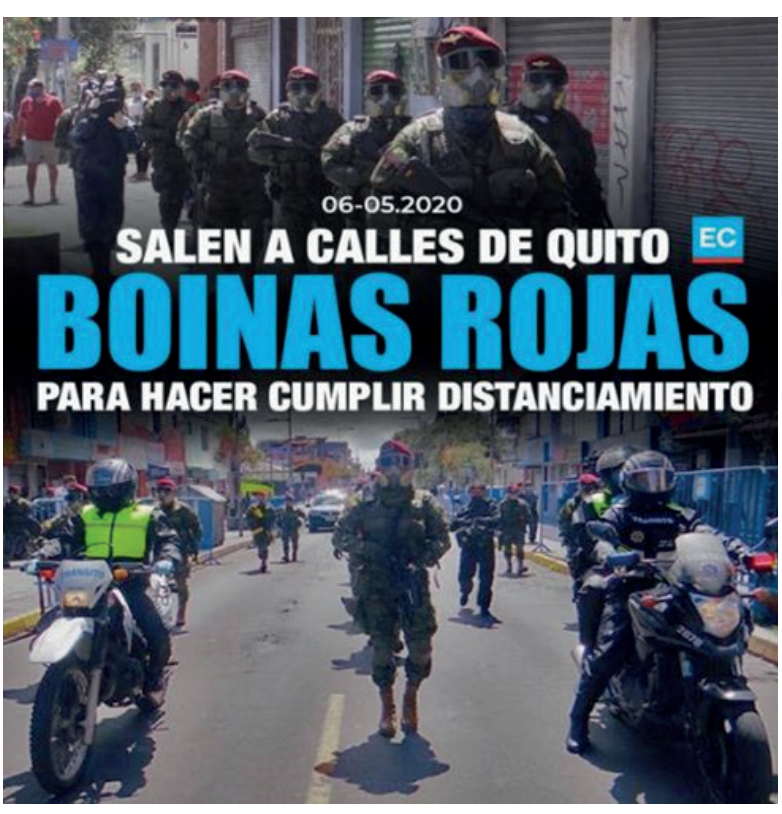

Figura 6. Los medios de comunicación pública reconocieron la presencia militar en las operaciones de control. Estos medios ayudaron a difundir las operaciones realizadas.

Nota. Archivo fotográfico libre. El Comercio (mayo 5, 2020)

Las experiencias relevantes de estas operaciones militares implican un mayor profesionalismo y compromiso social de la institución militar con el resto de instituciones al servicio de la ciudadanía; en este sentido, la complementariedad y la coordinación de las instituciones dejaron traslucir la vocación, la motivación y el liderazgo transformador de unas Fuerzas Armadas que van articulándose a los nuevos retos y desafíos de la seguridad. Debe destacarse de igual modo las siguientes fortalezas de la interagencialidad:

- El aprovechamiento de la información como orientadora de las operaciones y de percepción ciudadana;

- La complementariedad en el mando y en el empleo de capacidades complementarias como garantía de controles integrales; lo que hacía que los controles sean integrales;

- La optimización de los recursos disponibles por parte de todas las instituciones basada en responsabilidad social y compromiso con los ciudadanos

- La articulación de un mando operativo que orientaba el esfuerzo y los lugares que debían ser controlados;

- El conocimiento y empleo de medios disponibles de las instituciones como el sistema de cámaras en toda la ciudad, instrumentos indispensables para el logro de óptimos resultados y,

- Las instituciones participantes, bajo la dirección de Fueras Armadas, cumplieron con sus respectivas tareas, en forma integradora y complementaria, con legalidad y legitimidad, para conseguir el objetivo principal: reducir la velocidad de contagios en el territorio de nuestra responsabilidad.

\section{Conclusiones}

La complejidad de la dinámica actual de la globalización demanda del empleo integral de todos los esfuerzos para poder enfrentar los efectos de las amenazas y riesgos que deben asumir los Estados en materia de seguridad, sobre todo atendiendo las demandas ciudadanas. Implica, así mismo, desafiar la mirada de lo conocido para desarrollar mejores perspectivas para la comprensión de las problemáticas multidimensionales de la seguridad (amenazas emergentes y diversos riesgos que pueden azotar a la humanidad) con nuevas herramientas teóricas y analíticas, como aquellas que se han develado en el desarrollo del estudio del caso presentado, que siendo particular, refleja las macro realidades que se viven a nivel global.

Es preciso considerar los nuevos escenarios operacionales en donde deben actuar las Fuerzas Armadas, la eficacia de sus unidades cumpliendo principios y valores institucionales al servicio del país. Las diferentes operaciones de interagencialidad militar corresponden y se alinean a las nuevas dimensiones de la conducción política del Estado, la conducción políticoestratégica de la defensa (Midena) y la conducción estratégica-militar (Comaco).

Tomando en cuenta los principios de multifuncionalidad, interoperatividad y ultramovilidad de las Fuerzas Armadas, que garanticen el poder enfrentarse a contingencias complejas a partir de los principios de coordinación y complementariedad con las instituciones del Estado.

Las características actuales de la seguridad pública de los Estados evidencian la imposibilidad de delimitar las fronteras de lo local, lo regional, lo externo, lo interno, lo nacional y lo global; motivo por el cual es tarea obligada de los Estados y demás actores de la sociedad interactuar de manera integral a través de la coordinación, la planificación y la ejecución de acciones en todos los niveles de la conducción del Estado para poder dar respuestas a los retos y desafíos del mundo VICA actual.

En el caso específico del aparecimiento de una amenaza biológica convertida en pandemia por el COVID 19, las Fuerzas Armadas han desempeñado, dentro de sus misiones complementarias, un trabajo profesional y comprometido con la coordinación oportuna para la sincronización interinstitucional, materializando acciones altamente profesionales y de servicio a la sociedad para proteger sus derechos, libertades y garantías apoyando en el caso concreto del C.O4 "CENTRAL" a la neutralización y mitigación de la pandemia por COVID 19 en el ámbito de su jurisdicción.

Las Fuerzas Armadas en sus niveles estratégicos, operativos y tácticos lograron la sincronización de capacidades y su sostenibilidad con el resto de las instituciones estatales vinculadas con el control de la pandemia (Ministerio de Salud, Secretaría de Gestión de Riesgos, COE Nacional, Provincial y Cantonal, 
Gobiernos Autónomos Descentralizados, Ministerio de Inclusión Económica, ECU 911, entre otras).

Los efectos ocasionados por el impacto de la pandemia de la COVID 19 ocurrieron en el momento propicio para disponer de acciones cooperativas $\mathrm{y}$ complementarias mediante el diseño de una estructura orientadora de los esfuerzos de todos los actores, con lo cual se lograron resultados altamente positivos encaminados al cumplimiento del control efectivo de la pandemia, que aún se encuentra en proceso, dado que la mutación del virus ha detonado nuevas alertas, dentro de lo que algunos expertos denominan la "segunda ola" de la expansión de la COVID 19.

Las operaciones conducidas en el Comando Operacional No. 4 "CENTRAL" demostraron la efectividad que se logra cuando las instituciones se integran con un solo fin. La complementariedad permite dar legalidad y legitimidad a las operaciones, y se proyecta en la ciudadanía una imagen de control y orden que influye directamente en un sentimiento de mayor seguridad y tranquilidad por parte de los ciudadanos.

La problemática actual es compleja, la urbanización del conflicto es inminente, el empleo de las instituciones de control de forma integrada crea las condiciones favorables para que se tomen las decisiones de manera anticipada y oportuna, y se encuentren las mejores soluciones ante los diversos tipos de conflicto y situaciones disruptivas, que están marcando la dinámica del mundo actual.

\section{Referencias}

Booth, K. (2004). Critical Security Studies and World Politics. Lynne Rienner Publishers.

“CENTRAL,” C. 4. (2020). INFORME FINAL COVID -19. QUITO.

Comando de Educación y Doctrina Militar Terrestre. (2020). Manual Fundamental del Ejército. Apoyo a las Instituciones del Estado. Quito: Ejército Ecuatoriano.

Comando de Educación y Doctrina Militar Terrestre. (2020). Apoyo a las instituciones del Estado (AIE)MFE 3.01. Ejército Ecuatoriano.

Durán Segura, L. A. (ENRO-JUNIO de xiv (2015)). Poder, un esbozo foucaultiano. Revista ESPIGA (29), 55-70. Recuperado el 10 de enero de 2021, de https:// dialnet.unirioja.es/servlet/articulo? codigo $=5340166$

Foucault, M. (2015). The Punitive Society. (Palgrave. Macmillan, Ed.). Londres.

Francoe, A. M. (2007). La coordinación interagencial: el arma secreta de la Seguridad Democrática. Revista Estudios en Seguridad y Defensa, 2(3), 3444. Obtenido de https://esdeguerevistacientifica.edu. co/index.php/estudios/article/view/153/217

Frasson-Quenoz, F. (2015). Autores y teorías de Relaciones Internacionales: una cartografía. Universidad Externado de Colombia.

Fuel, F. (2020). COVID -19. Cronología de una Crisis. (GRAFICIENTRO, Ed.) (1st ed.). Quito.
Gaebler, D. O. (1992). Reinventing Government. How the Entepreneurial Spirit is Transforming the Public Sector. Adisson Wesley PUbl. Co.

Equipo de Planificación y Coordinación Interinstitucional (2019). Plan Nacional de Seguridad Integral 20192030. Instituto Geográfico Militar.

Manucci, M. (2010). Contingencias. 5 desafios de cambio para una nueva década. Grupo Editorial Norma.

Ministerio de Defensa Nacional. (2018a). Agenda e Coordinación Intersectorial de Seguridad. (IGM, Ed.). IGM.

Ministerio de Defensa Nacional. (2018b). AGENDA POLITICA DE LA DEFENSA ECUADOR. (IGM, Ed.) (1st ed.). QUITO: IGM.

Moncayo, P. (2019). Seguridad y Defensa en la Historia ecuatoriana. Casa de la Cultura Ecuatoriana.

Asamblea Nacional del Ecuador (2014). Ley de Seguridad Pública y del Estado (2009. Reforma de 2014). Asamblea Nacional .

Shambach, S. (2004). Strategic Leadership Primer. (United States Army War College, Ed.) (2ND EDITIO). United States Army War College.

Varela, F. y Maturana H. (1980). Autopoiesis and Cognition: The Realization of Living. D. Reidel Publishing Company. 